\title{
O pensamento pedagógico de Paulo Freire à luz da filosofia da educação
}

Gonçalves, José Luís A. ${ }^{1}$

\begin{abstract}
Resumo
Propomo-nos analisar neste artigo o pensamento pedagógico de Paulo Freire na ótica da filosofia da educação. Entendendo-se esta área de saber, simultaneamente, como reflexão tanto das problemáticas educacionais (no plano epistemológico e hermenêutico) como das problemáticas educativas (dimensão ética e antropológica) presentes no discurso pedagógico de Paulo Freire, a nossa análise assentará numa circularidade epistemo-antropológica deste pensamento. Dito de outra forma, é nossa intenção caracterizar a relação estreita que estabelecem entre si uma epistemologia da práxis e uma antropologia dialógica no pensamento pedagógico deste grande educador.
\end{abstract}

Filosofia da educação. Epistemologia da práxis. Antropologia dialógica.

\begin{abstract}
o
En este artículo nos proponemos examinar el pensamiento pedagógico de Paulo Freire en la perspectiva de la filosofía de la educación. La comprensión de esta área del conocimiento refleja tanto el problema educacional (el epistemológico y el plano hermenéutico) como las cuestiones educativas (dimensión ética y antropológica) presentes en el discurso pedagógico de Paulo Freire. Nuestro análisis hestara basado en una circularidad epistémica-antropológica de su pensamiento. Dicho de otra manera, tenemos la intención de caracterizar la estrecha relación que se establece entre una epistemología de la práxis y una antropología dialógica en el pensamiento pedagógico de este gran educador.
\end{abstract}

Filosofía de la educación. Epistemología de la praxis. Antropología dialógica.

\footnotetext{
${ }^{1}$ Diretor da Escola Superior de Educação de Paula Frassinetti, Porto, Portugal; investigador do Gabinete de Filosofia da Educação do Instituto de Filosofia da Faculdade de Letras da Universidade do Porto (UI\&D/Fil/00502) e do Centro de Investigação de Paula Frassinetti (CIPAF), Portugal. E-mail: joseluis@esepf.pt
}

Interritórios | Revista de Educação Universidade Federal de Pernambuco Caruaru, BRASIL | V.2 | N.2 [2016] 


\section{Filosofia da educação: para uma crítica da razão educativa}

Enquanto labor reflexivo sobre o pensamento da educação e as regras de formação dos seus enunciados, a Filosofia de educação levanta a hipótese epistemológica de haver uma razão educativa por detrás de todo o discurso pedagógico e de ser possível encontrar-Ihe uma unidade de sentido. Esta abordagem do pensamento sobre a educação não pretende, todavia, eliminar as contradições ou reparar as inconsistências que nascem no interior dos discursos e práticas pedagógicas. Antes visa fazer emergir "[um] 'pensamento de educação' ao conjunto de produções teóricas que tratam da educação [...], ou seja, [identificar-Ihe] o discurso sobre os fundamentos, os fins, os valores. E reserva-se então a expressão filosofia da educação à análise deste pensamento, ao pensamento deste pensamento. Todo o alcance filosófico parece-nos estar nesta reduplicação reflexiva, ou mais exatamente, 'criticista' no sentido kantiano [do termo]". (Cf. N. CHARBONNEL, 1988, pp. 173-174).

A análise a algumas dimensões do pensamento pedagógico de Paulo Freire que nos propomos levar a efeito neste artigo acontece à luz desta concepção de filosofia da educação, isto é, estrutura-se enquanto crítica da razão educativa com o objetivo de evidenciar modestamente algumas virtualidades conceptuais de que o seu pensamento é portador. Este desiderato evidencia-se tanto mais complexo quanto é sabido que as linhas teóricas que sustentam o pensamento de Paulo Freire resultam mais das reflexões inspiradas no seu percurso biográfico e nas situações históricoexistenciais (situações-limite) vividas, do que das leituras sistemáticas realizadas pelo autor a obras de referência. Embora enumere em alguns escritos as leituras feitas e os autores estudados, a exemplo da Pedagogia da Esperança, a coerência entre vida e teoria constitui a grande fonte inspiradora do seu pensamento pedagógico.

Fiel a esta aceção, focalizar-nos-emos não tanto sobre a 'pedagogia' de Paulo Freire - quando entendida como corpo teórico hermético e representativo de princípios doutrinários constantes a serem aplicados na prática educativa -, mas sobre 'o pedagógico' do seu pensamento, incidindo, então, a nossa atenção, preferencialmente, sobre as propostas teóricas e os 
conceitos que veiculam, secundarizando, sem menosprezar, as suas relações com a prática. Nesta perspetiva, importam mais as estruturas conceptuais que preconiza que os factos que arrola, interessa mais analisar o campo históricoproblemático em que se move o pensador e menos o avanço socioeducativo alcançados por uma determinada ideia.

A compreensão das suas ideias pedagógicas far-se-á à luz de uma crítica kantiana da razão educativa, isto é, para fazer jus ao que se disse atrás, deseja-se que abordagem filosófica não seja apenas epistemológica, "mas que tenha em conta o conteúdo ontológico daquilo sobre o qual se está a refletir". (CHARBONNEL, 1988, p. 143). Nesse sentido, a abordagem 'filosófica' preconizada neste artigo caracteriza-se por ser holística (nenhum domínio escapa à interrogação filosófica), radical (pretende ir à raiz dos problemas) e vital (a crítica não se contenta com o interesse especulativo) (REBOUL, 2000).

Clarificando os pontos de partida da nossa análise, esclarece-se que usaremos no contexto deste artigo o conceito de epistemologia no sentido empregue por Octavi Fullat i Génis (1997) para designar o conjunto dos saberes em geral e não só os assim denominados 'científicos'. A nossa análise não incidirá, portanto, sobre um tipo de verdade empírica ou da realidade que as obras evocadas porventura possam querer evidenciar, e também não assentará na análise axiomática de verdades formais ou de coerência nelas contidas. Valorizaremos antes as verdades existenciais ou de sentido extraídas dos conceitos em apreciação, verdades essas que se apoiam preferencialmente no compromisso pessoal e/ou coletivo de alguém que os viveu de forma significativa-comprometida como foi o caso de Paulo Freire.

Como existem tantos tipos de verdade quantas as modalidades de conhecimento, e a cada tipo de saber corresponde uma metodologia apropriada, a nossa análise crítica dos conceitos freirianos não incidirá, como anteriormente dito, sobre os saberes empíricos neles vertidos e que recorrem aos métodos redutivos-indutivos, nem tão pouco sobre os saberes formais preconizados pelo autor e que trabalham com o método axiomático-dedutivo. 
Antes, pretendemos destacar os saberes de sentido que emergem do pedagógico do seu discurso e que se extraem do mesmo preferencialmente através dos métodos hermenêuticos e fenomenológicos. É, pois, nossa intenção interpretar o significado educacional/educativo do discurso freiriano para lhe perscrutar as configurações do humano de que é portador. Dito de outra forma, interessa-nos indagar em que medida "o humano e o educacional constituem «significantes-significados» mutuamente referidos". (FULLAT । GÉNIS, 1997, p. 16) no pensamento freiriano.

\section{Por uma epistemologia da práxis - a matriz filosófica hegeliana do pensamento pedagógico freiriano}

Um breve levantamento dos conceitos-chave mobilizados por Freire nas suas obras (e.g., práxis, sujeito-objeto, conscientização, oprimido, ser alienado, etc.) remete-nos para um conjunto de pensadores conhecidos em que ele se inspira ou nos quais enxerta e reelabora determinadas noções e/ou conceitos, designadamente em Kant, Fichte, Jaspers, Bloch, Buber, Fromm, Dewey, Bachelard, entre outros. No entanto, está evidenciado que a matriz filosófica do seu pensamento mergulha as suas raízes prioritariamente na tradição do pensamento dialético de inspiração hegeliana (WOHLFART, 2013). Disso dá conta, a título exemplificativo, a conceção e a estrutura epistemológica desenvolvida por Paulo Freire na Pedagogia do Oprimido, escrito que segue de perto o sistema filosófico de Hegel patente nas obras Ciência da Lógica e Enciclopédia das Ciências Filosóficas. Deve destacar-se, neste contexto, especialmente a dialética da subjetividade e da objetividade preconizada por ambos quando referida à construção da noção filosófica de conhecimento.

Assim, quer em Hegel quer em Freire, na circularidade dialética da estrutura epistemológica veiculada, a objetividade resulta da exteriorização e concretização da subjetividade na forma da "diferença" fora de si; por sua vez, a subjetividade constitui-se a partir deste processo de exteriorização do sujeito na objetividade mas agora enquanto movimento de consciente de "retorno" a si. Dito nas palavras de Paulo Freire, "a consciência do mundo 
constitui-se na relação com o mundo; não é parte do eu. O mundo, enquanto "outro" de mim, possibilita que eu me constitua como "eu" em relação a "você". [...] A consciência do mundo, tocado e transformado, é que gera a consciência do eu". (FREIRE \& MACEDO, 1994, p. 39). A noção de método empregue por Hegel ampara teoricamente a integração permanente entre subjetividade e objetividade que Paulo Freire advoga e defende:

A objetividade dicotomizada da subjetividade, a negação desta na análise da realidade ou na ação sobre ela, é objetivismo. Da mesma forma, a negação da subjetividade, na análise como na ação, conduzindo ao subjetivismo que se alonga em posições solipsistas, nega a ação mesma, por negar a realidade objetiva, desde que esta passa a ser criação da consciência. Nem objetivismo, nem subjetivismo ou psicologismo, mas subjetividade e objetividade em permanente dialeticidade. (FREIRE, 1987, p. 41).

Ampliando este processo dialético para a relação entre sujeitos, Freire preconiza que o oprimido só será capaz de compreender os mecanismos psicossociais que concorrem para a introjeção do opressor na sua mente e identificar os obstáculos epistemológicos em objetivar o opressor como um outro por esta via:

Só no entendimento dialético de como [...] se dão consciência e mundo é possível compreender o fenômeno da introjeção do opressor, a aderência deste àquele, a dificuldade que tem o oprimido de localizar o opressor fora de si, oprimido. (FREIRE, 2000a, p. 106).

A sua fonte de inspiração situa-se em Hegel na medida em que este filósofo se propôs pensar as condições históricas de efetivação da liberdade capaz de fazer a síntese entre as dimensões da individualidade e da sociabilidade do ser humano, por via do reconhecimento intersubjetivo nas várias esferas da vida coletiva. Socorre-se, por isso, da dinâmica de reconhecimento estabelecida entre dominado e dominador patente na Dialética do Senhor e do Escravo (Hegel, Fenomenologia do Espírito) para extrapolar esse paralelismo para a esfera pedagógica da relação que entretêm professor e aluno na educação bancária versus educação libertadora. Hegel, na Fenomenologia do Espírito, contribuirá decisivamente para compreensão das implicações morais do reconhecimento ao estabelecer 
simultaneamente uma conexão obrigatória entre autoconsciência e reconhecimento intersubjetivo e um vínculo necessário entre esta aquisição intersubjetiva da autoconsciência e o desenvolvimento moral das sociedades inteiras. Esta mesma lógica é seguida por Paulo Freire nas suas mais variadíssimas obras.

A educação libertadora de Paulo Freire é potenciada pela noção de conscientização e somente operacionalizável através de uma metodologia dialógica e problematizante (Conforme Pedagogia do Oprimido) da experiência do aprender capaz de construir conhecimento, tem por objetivo desenvolver a consciência crítica das pessoas, para que sejam capazes de conhecer a realidade, de a interpretar e, agindo sobre ela mediante opções comprometidas, transformar o mundo tornando o educando sujeito da sua história. O processo educativo de cariz emancipatório-libertário que o pensamento freiriano preconiza pressupõe, pois, o compromisso com uma práxis transformadora: "Na medida em que o compromisso não pode ser um ato passivo, mas práxis - ação e reflexão sobre a realidade - inserção nela, ele implica indubitavelmente um conhecimento da realidade". (FREIRE, 1983, p. 21). A verdadeira práxis transformadora acontece quando existe consciência crítica e esta "somente se dá com um processo educativo de conscientização" [...somente] na [consciência] crítica há um compromisso". (Freire, 1983, p. 39). Como muitas outras noções ou conceitos, a expressão freiriana conscientização faz jus à matriz da filosofia hegeliana quando este pensador explica que "a conscientização não pode existir fora da práxis, ou melhor, sem o ato ação-reflexão. Esta unidade dialética constitui, de maneira permanente, o modo de ser ou de transformar o mundo que caracteriza os homens. Por isso mesmo, a conscientização é um compromisso histórico". (FREIRE, 1980, p. 26).

\section{Antropologia freiriana: a dialogicidade entre 0 inacabamento humano e a esperança da libertação}

A imbricação implícita entre conceções do humano e da educação - isto é, a relação que entretêm entre si antropologia e pedagogia - constitui um 
dos postulados-chave em filosofia da educação. Ancorados, pois, na afirmação de Kant de que o homem é o que é unicamente pela educação, concebe-se, portanto, a educação como projeto antropológico. E se toda a práxis educadora pressupõe uma antropologia, é lícito afirmar que paideia e anthropos amparam-se e sustentam-se mutuamente, abrindo-se, em filosofia da educação, o processo educativo a uma circularidade epistemoantropológica de grande importância. (CARVALHO, 1998, p. 14). Para que a educação tenha este pendor antropológico, a filosofia da educação demarcase "por um lado, da redução da filosofia a um papel epistemológico e, por outro, da sua identificação como hermenêutica da ação. Deste respeito e distanciamento resultará a identidade antropológica primordial da ideia de educação". (Ibidem, p. 14).

Os mais diversos autores que ajudarem a por de pé a história do pensamento educacional sempre entenderam a educação como um processo e/ou uma passagem intencional do homem condicionado (natureza) para a liberdade (cultura), ora entendida como libertação da ignorância e condição de participação na polis (Platão) ou, como defende Kant, um processo de abandono da animalidade/menoridade e aprendizagem para a decisão autónoma-esclarecida. A antropologia freiriana situa-se, neste âmbito, próxima destas conceções, designadamente a kantiana quando Paulo Freire deseja encontrar o fundamento antropológico para o processo educativo:

[...] Tratemos de encontrar, na natureza do homem, algo que possa construir o núcleo fundamental onde se sustente o processo de educação. [...] Este núcleo seria o inacabamento ou a inconclusão do homem. [...] A educação é uma resposta da finitude da infinitude. A educação é possível para o homem, porque este é inacabado e sabe-se inacabado. Isto leva-o à sua perfeição. (FREIRE, 1983, pp. 27-28).

Em razão da autoconsciência do seu inacabamento e intuindo as possibilidades da sua humanização, a condição antropológica do Homem freiriano é a de ser homo educandus:

É na inconclusão do ser, que se sabe como tal, que se funda a educação como processo permanente [...]. É também na inconclusão de que nos tornamos conscientes e que nos 
inserta no movimento permanente de procura que se alicerça a esperança. (FREIRE, 1996, p. 64).

Postula o autor, pois, a educabilidade do homem o que, por sua vez, remete para as características de maleabilidade e da plasticidade do processo educativo, afinal, condição da sua perfetibilidade, como recorda em registo kantiano, A. D. Carvalho:

É aqui que a educação desempenha o seu papel antropologicamente decisivo: não constituindo um fim em si, ela é, todavia, imprescindível para o cumprimento do homem como fim em si mesmo. [...] A educação serve, pois, a construção de um homem definido pelo seu futuro: antecipa a humanidade futura - o que the confere sentido - porque o homem tem necessidade da educação para concretizar a sua liberdade e se instituir como ser moral. (CARVALHO, 1990, pp. $145 \mathrm{ss})$.

Paulo Freire insere-se, com todo o mérito, na linha dos grandes pedagogos do século XX, e na opinião de Enrique Dussel (2002, pp. 422430), "supera até outros nomes consagrados como Piaget, Vygotsky ou até Kohlberg pelo caráter relacional-dialógico que imprime a todo o processo educativo". Contra uma perspetiva mais individualista do desenvolvimento humano, Paulo Freire advoga a humanização da pessoa no ato de aprender como estando umbilicalmente ligada à qualidade da relação intersubjetiva estabelecida entre os sujeitos em diálogo. O processo de humanização é potenciado pela problematização em educação e acontece na relação dialógica dos sujeitos: "O que se pretende com o diálogo [...] é a problematização do próprio conhecimento em sua indiscutível reação com a realidade concreta na qual se gera e sobre a qual incide, para melhor compreendê-la, explicá-la, transformá-la”. (FREIRE, 1992, p. 52). Daí que a ação dialógica seja, em si, uma ação transformadora, por via da educação:

ao contrário do que ocorre na teoria anti-dialógica da ação, que mitifica a realidade para manter a dominação, na colaboração, exigida pela teoria dialógica da ação, os sujeitos dialógicos se voltam sobre a realidade mediatizadora que, problematizada, os desafia. A resposta aos desafios da realidade problematizada é já ação dos sujeitos dialógicos sobre ela, para transformá-la. (FREIRE, 1987, p. 167). 
Reside na força deste diálogo a condição de possibilidade de humanização do próprio Homem por via da construção da sua autonomia pessoal e profissional que,

enquanto amadurecimento do ser para si, é processo, é vir a ser. Não ocorre em data marcada. É neste sentido que uma pedagogia da autonomia tem de estar centrada nas experiências estimuladoras da decisão e da responsabilidade, vale dizer, em experiências respeitosas da liberdade. (FREIRE, 1996, p. 121).

Nasce de uma matriz crítica e gera criticidade (Jaspers). "[...] Nutre-se do amor, da humildade, da esperança, da fé, da confiança. Por isso, só o diálogo comunica". (FREIRE, 2000, p. 115). Em síntese, a antropologia marcadamente personalista de Paulo Freire propõe uma pessoa que se entende a partir da comunicação interpessoal (Mounier) e na dimensão relacional pela via dialógica (Buber). Uma característica antropológica marcante da filosofia de educação de Paulo Freire ligada ao inacabamento da condição humana é a esperança. A esperança

faz parte da natureza humana. Seria uma contradição se, inacabado e consciente do inacabamento, primeiro, o ser humano não se inscrevesse ou não se achasse predisposto a participar num movimento constante de busca e, segundo, se buscasse sem esperança. A esperança é uma espécie de ímpeto natural possível e necessário [...], condimento indispensável à experiência histórica. Sem ela, não haveria História, mas puro determinismo. Só há História onde há tempo problematizado e não pré-datado. A inexorabilidade do futuro é a negação da História. (FREIRE, 1996, pp. 80-81).

Este conceito teológico-filosófico é trabalhado por Freire muito próximo da conceção de esperança defendida por Ernst Bloch quando este a alia ao conceito de práxis. Na reinterpretação que $\mathrm{E}$. Bloch faz das obras do jovem Marx, recupera-lhe os traços humanistas da sua proposta e junta-lhe o significado da esperança enquanto princípio utópico: "este é e continuará sendo o caminho do socialismo, a práxis utópica concreta. Todo o não-ilusório e o realmente possível nas imagens da esperança remontam a Marx". (BLOCH, 2005, p. 27). Na esteira de E. Bloch, que articula a esperança com os conceitos de antecipação, de utopia e de práxis, Freire consegue integrar 
esta dimensão no projeto de uma epistemologia da práxis, erigindo a característica antropológica da esperança como condição da transformação pessoal e social: "Enquanto necessidade ontológica, a esperança precisa da prática para tornar-se concretude histórica. É por isso que não há esperança na pura espera”. (FREIRE, 2000a, p. 11). Assim, a educação libertadora é práxis quotidiana da efetivação da liberdade (conforme Hegel), na medida em que "a libertação autêntica, que é a humanização em processo, não é uma coisa que se deposita nos homens. Não é uma palavra a mais, oca, mitificante. É práxis, que implica ação e a reflexão dos homens sobre o mundo para transformá-lo". (FREIRE, 1987, p. 67).

\section{Conclusão}

A crítica filosófica da razão educativa que perscruta o pensamento pedagógico de Paulo Freire permite destacar a relação estreita e mutuamente implicada entre as dimensões epistemológica e antropológica presentes no seu conceito de educação. A centralidade que ocupa a relação intersubjetiva no processo de conscientização por via da educação e o papel insubstituível que o diálogo adquire nesse processo instituem-no - ao diálogo - como princípio metodológico e epistemológico por excelência. Quando aplicado ao processo de ensino-aprendizagem não-diretivo, pode concluir-se que

saber ensinar não é transferir conhecimento, mas criar as possibilidades para a sua própria produção ou a sua construção. [...] Este saber necessário ao educador não apenas precisa de ser apreendido por ele e pelos educandos nas suas razões de ser - ontológica, política, ética, epistemológica, pedagógica -, mas precisa também de ser constantemente testemunhado. (FREIRE, 1996, p. 47).

$\mathrm{Na}$ perspetiva freiriana, a práxis verdadeiramente transformadora (da Natureza, do Homem e da Sociedade) há de dar conta do compromisso que a educação evidencia com a libertação gradual do Homem dos condicionalismos que impedem a sua humanização. O Homem "é um ser da "práxis"; da ação e da reflexão. [...] Se encontra marcado pelos resultados da sua própria ação". (FREIRE, 1992, p. 28). A pedagogia da esperança 
comprometida veiculada por Paulo Freire permite alimentar expectativas fundadas na transformação do mundo:

Contra toda a força do discurso fatalista neo-liberal, pragmático e reacionário, insisto hoje, sem desvios idealistas, na necessidade da conscientização. Na verdade, enquanto aprofundamento da 'prise de conscience' do mundo, dos factos, dos acontecimentos, a conscientização é exigência humana, é um dos caminhos para a posta em prática da curiosidade epistemológica. (FREIRE, 1996, p. 54).

\section{Referências}

BLOCH, E. . O princípio esperança. Rio de Janeiro: UERJ/Contraponto, v. 1, 2005.

CARVALHO, A. D. Educação como Projecto Antropológico. 2. Ed. Porto: Edições Afrontamento (Biblioteca das Ciências do Homem/Ciências da Educação; 7), 1998.

A educabilidade como dimensão antropológica. Filosofia. Revista da Faculdade de Letras da Universidade do Porto, vol. 7, 1990, pp. 145-156.

CHARBONNEL, N.. Pour une Critique de la Raison Pédagogique. Berna: Peter Lang, 1988.

DUSSEL, E.. Ética de la liberación en la edad de la globalización y de la exclusión. Madrid: Trotta, 2002.

FREIRE, P.. Pedagogia da Esperança. 7. ed. Rio de Janeiro: Paz e Terra, 2000a. Terra, 2000b.

Educação como Prática da Liberdade. 24. ed. Rio de Janeiro: Paz e Pedagogia da Autonomia: saberes necessários à prática educativa. Rio de Janeiro: Paz e Terra, 1996.

Extensão ou Comunicação? 10. ed. Rio de Janeiro: Paz e Terra, 1992.

Pedagogia do Oprimido. 17. ed. Rio de Janeiro: Paz e Terra, 1987.

Educação e Mudança. 7. ed. Rio de Janeiro: Paz e Terra, 1983.

Moraes, 1980.

Conscientização: teoria e prática da libertação. 3. ed. São Paulo: Ed.

Acção Cultural para a Libertação e os escritos. Portugal: Moraes Editores, 1977.

FREIRE, P. \& MACEDO, D. . Alfabetização: leitura do mundo e leitura da palavra. 2. ed. Rio de Janeiro: Paz e Terra, 1994. 
FULLAT I GÉNIS. O. . Antropología Filosófica de la Educación. Barcelona: Editorial Ariel Educación, 1997.

GONÇALVES, J. L. . Aprender na e com a vida - a problematização da experiência como processo de consciencialização. In Cadernos de Pedagogia Social. Lisboa: Universidade Católica Editora, n. 3, ano III, 2009, pp. 35-44,.

WOHLFART, J. A.. Fundamentos Dialéticos da Pedagogia do Oprimido. Editora IFIBE, Coleção Diá-Logos, 2013.

REBOUL, O.. A Filosofia da Educação. Lisboa: Edições 70, 2000. 